\title{
Features of 3-7-day planetary-wave-type oscillations in F-layer vertical drift and equatorial spread $F$ observed over two low-latitude stations in China
}

\author{
Zhengping Zhu, Weihua Luo, Jiaping Lan, and Shanshan Chang \\ College of Electronics and Information Engineering, South-Central University for Nationalities, Wuhan 430074, China
}

Correspondence to: Zhengping Zhu (zpzhu2007@sina.com)

Received: 5 January 2017 - Revised: 17 April 2017 - Accepted: 23 May 2017 - Published: 22 June 2017

\begin{abstract}
Recent studies on the equatorial atmosphereionosphere coupling system have shown that planetarywave-type oscillations, as an important seeding mechanism for equatorial spread $\mathrm{F}$ (ESF), play an important role in ESF irregularity development and its day-to-day variability in the equatorial latitudes. In this study, ionosonde virtual height and ESF measurements over Sanya $\left(18.4^{\circ} \mathrm{N}\right.$, $109.6^{\circ} \mathrm{E} ; 12.8^{\circ} \mathrm{N}$ dip latitude) and meteor radar neutralwind measurements over Fuke $\left(19.5^{\circ} \mathrm{N}, 109.1^{\circ} \mathrm{E} ; 14^{\circ} \mathrm{N}\right.$ dip latitude) during 2013 are used to investigate the features of planetary-wave-type oscillations in both the lower atmosphere and the ionosphere and their possible influences on ESF occurrence under the weak solar maximum year. The $\sim$ 3-day and $\sim 7$-day planetary-wave-type oscillations have been observed in the neutral zonal winds and the time rate of change in F-layer virtual heights. According to the propagation characteristics, the 3-day and 7-day planetary-wavetype oscillations are basically recognized as ultrafast and fast Kelvin waves, respectively. With increasing heights, the 3day wave oscillations are gradually amplified, while the 7day wave oscillations are generally constant. By performing a cross-wavelet transform on the onsets of ESF and the vertical drifts of the F layer, we found that there are simultaneously occurring 7-day and 3-day common wave oscillations between them. The 7-day waves are mainly in the inversion phase, while the 3-day waves are mostly in an in-phase state, indicating that the 7-day waves may play a main role in ESF initiation. Approximate delays of 6 days for the 7-day waves and 5 days for the 3-day waves in their propagation upward from the lower atmosphere to the ionosphere are evaluated with wavelet power spectrum analysis. The estimated upward velocities from these time delays provide consistent evidence that the 7-day and 3-day waves propagate vertically upward
\end{abstract}

with typical Kelvin wave characteristics. The results highlight the role of planetary-wave-type oscillations in the initiation and development of ESF in the Chinese low-latitude region.

Keywords. Ionosphere (equatorial ionosphere)

\section{Introduction}

The equatorial spread-F (ESF) plasma irregularities mainly occurring in the equatorial and low-latitude ionosphere have been the theme of many studies since the late 1930s (Booker and Wells, 1938). They are now becoming an important subject in space weather research due to their impacts on satellite navigation and communication application systems.

It is commonly accepted that the basic mechanism responsible for ESF irregularities is the generalized RayleighTaylor (RT) instability. To trigger the RT instability, however, a source is needed to act on the F-layer bottom to generate a small perturbation in the electron density. An important candidate is the vertical coupling processes driven by upwardpropagating atmospheric waves (tidal, gravity and planetary waves), which originate from the lower atmosphere. Gravity waves generated in the troposphere by meteorological activity with periods ranging from minutes to hours generally propagate upward into the mesosphere and the lower thermosphere (MLT) and could play an important role in seeding the ESF. A recent study by Li et al. (2016) showed that there is a good correlation between the intertropical convergence zone (ITCZ) convective activity and ESF generation rates. Planetary-wave-type oscillations have global scales with periods varying from 2 to 30 days usually observed in the 
neutral atmosphere and the ionosphere. Also, as many researchers have suggested, planetary-wave-type oscillations have significant effects on the development of small- and large-scale structures and the formation of ESF and plasma bubble irregularities. During this process, the evening prereversal vertical drift enhancement (PRE) is considered a key link in the near-equator region during sunset hours (Abdu et al., 2003, 2006b; Abdu, 2005; Li et al., 2007). Thus the effects of planetary-wave-type oscillations as seeding mechanisms for ESF have been investigated mainly by studying their behavior in PRE (Abdu et al., 2006a; Takahashi et al., 2006; de Abreu et al., 2014a), E-layer conductivity (Abdu and Brum, 2009) and the dynamo-electrical fields (Bertoni et al., 2011). Planetary-wave-type oscillations also directly modulate the onset time of ESF (Fagundes et al., 2009; Takahashi et al., 2009). In addition, traveling planetary-wave-type ionospheric disturbances (TPWIDs) have been reported in GPS phase fluctuations with an important role in the generation of ESF (de Abreu et al., 2014b).

Usually, planetary wave characteristics are investigated by studying their features in different height regions, especially in the MLT area. The measurements of MLT neutral winds (meridional and zonal components) have proven to be powerful tools for diagnosing wave behavior at these heights. For example, in the equator area, Kovalam et al. (1999) discovered planetary-scale wave oscillations by using the zonal and meridional winds measured by MF radars in the mesosphere and lower thermosphere at two sites separated by $94^{\circ}$ in longitude. In the low latitudes with the meteor radar wind measurements, quasi-2-day planetary waves in the meridional component (Lima et al., 2004) and quasi-2-day waves in the meridional component accompanied by 3-7-day waves in the zonal component (Pancheva et al., 2004) were also reported. In the middle-to-low latitudes from the simultaneous observations of two meteor radar atmospheric neutral winds, a westward-propagating quasi-2-day planetary wave was observed (Lima et al., 2007). With temperature data from TIMED-SABER (Thermosphere, Ionosphere, Mesosphere Energetics and Dynamics; Sounding of the Atmosphere using Broadband Emission Radiometry), Pancheva et al. (2009) detected planetary-scale waves from the stratosphere to the lower thermosphere during the Arctic winter of 2003-2004. Also with TIMED-SABER global temperature data for 2002-2012, Xu et al. (2014) studied the nonlinear interaction between stationary planetary waves (SPWs) and tides in the stratosphere and mesosphere. Since there are regular variations in tidal wave amplitude with periods of the sum and differences in planetary-scale and tidal waves, the interactions between them are properly investigated. For instance, the nonlinear interactions between diurnal and semidiurnal tides and planetary waves are successively confirmed (Beard et al., 1999; Pancheva, 2000). The clear anticorrelation between the diurnal tide and the quasi-2-day wave was recognized by Gurubaran et al. (2001), who present their interactions. Pancheva et al. (2002b) also found modulations in the amplitude of the $12 \mathrm{~h}$ tide caused by 10 - and 16-day planetary waves. Xu et al. (2012) presented the thermal forcing of the semidiurnal, terdiurnal and $6 \mathrm{~h}$ components of the migrating tide induced by ozone heating in the stratosphere and lower mesosphere by using data from the Microwave Limb Sounder (MLS) instrument on the Aura satellite.

At ionospheric heights, planetary-wave-type oscillations usually appear as modulating key ionospheric parameters, such as $f o \mathrm{~F}_{2}, h m \mathrm{~F}_{2}, f o$ Es, Es-layer formation and multifrequency virtual height variations (Pancheva et al., 2002a, 2003; Laštovička et al., 2003; Haldoupis et al., 2004; Fagundes et al., 2005; Polekh et al., 2011). Planetary-wave-type oscillations have also been found in GPS total electron content (Chang et al., 2011) and $\mathrm{S}_{4}$ scintillation indices (Liu et al., 2013).

Though planetary wave signatures have been extensively studied in the lower atmosphere and the ionosphere individually as mentioned above, planetary-scale oscillations with the same periods are also usually found to coexist at neutral atmospheric heights and near or above the ionosphere. For example, common planetary-scale oscillations are discovered to exist in the airglow emission intensity, the ionospheric F-layer bottom heights $\left(h^{\prime} \mathrm{F}\right)$ (Takahashi et al., 2005) and meteor radar winds as well as in ionospheric evening F-region vertical plasma drift (Abdu et al., 2006c). The coexistence of these phenomena indicates the vertical propagation of planetary waves. Laštovička (2006) pointed out that planetary-wave-type oscillations are propagated upwards to the F-region heights only indirectly via nonlinear interactions, like modulation of the upward-propagating tides in the middle-latitude region. On the other hand, Takahashi et al. (2007) suggested the propagation of a planetary-wavetype oscillation with a period of 3 to 4 days directly from the stratosphere up to the ionosphere in the low-latitude region.

Kelvin waves, one of the most common types of planetary waves, are trapped in the equator and low-latitude regions where the Coriolis force is negligible. They are usually divided into three types according to their periods: slow (about 16 days), fast (6 to 7 days) and ultrafast (3 to 4 days). Kelvin wave disturbances were first reported by Salby et al. (1984) in the stratosphere over the equator in two independent Nimbus-7 LIMS (Limb Infrared Monitor of the Stratosphere) data sets. With MF partial-reflection radars, ultrafast Kelvin waves in the mesospheric winds (Vincent and Lesicar, 1991), 3-10-day Kelvin wave oscillations in the equatorial mesosphere and lower thermosphere (Vincent, 1993), 3-day Kelvin waves in the equatorial mesosphere (Riggin et al., 1997) and 3.5-day ultrafast Kelvin waves in the mesopause region (Sridharan et al., 2002) were successively recognized. By using the HRDI (high-resolution Doppler imager) on the UARS (Upper Atmosphere Research Satellite) to measure mesosphere and lower thermospheric zonal winds, eastwardpropagating $\sim 3$ - and $\sim 5$-day Kelvin waves were discovered (Lieberman and Riggin, 1997). Also successively observed were 2-day Rossby gravity waves and 3.5-day Kelvin 


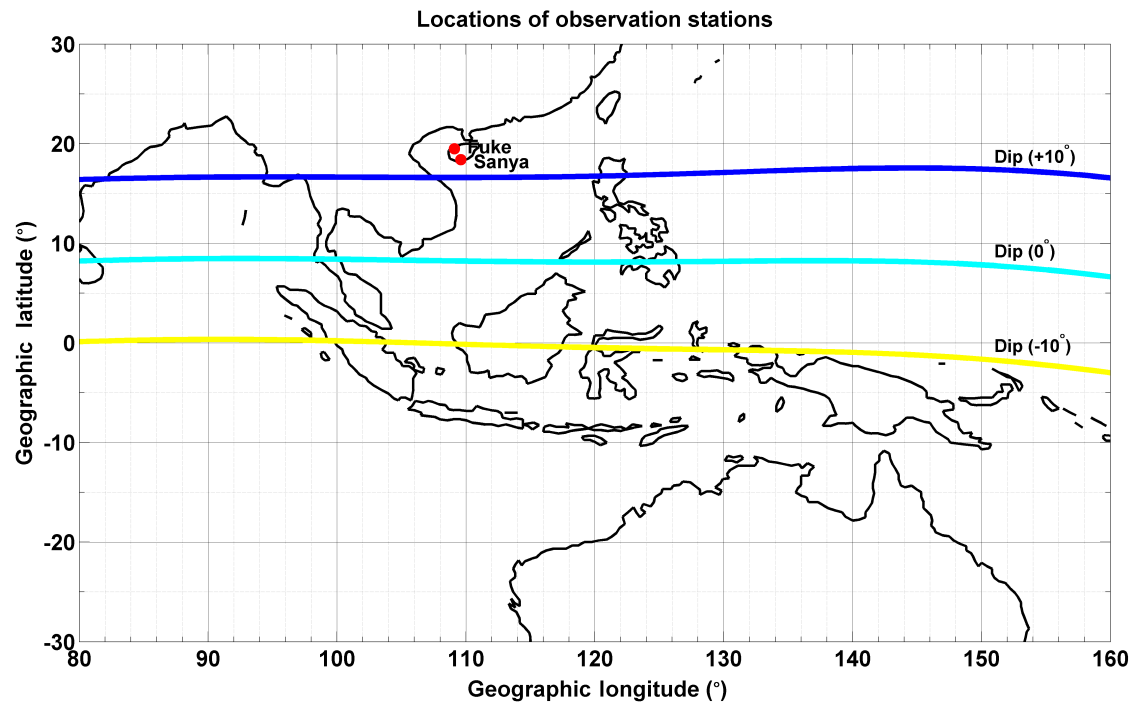

Figure 1. The location of the observation stations at Sanya and Fuke in China with the three typical magnetic latitudes (dip latitudes $10^{\circ} \mathrm{N}$, 0 and $10^{\circ} \mathrm{S}$ ) marked on the map.

wave oscillations in airglow photometer observations (Takahashi et al., 2002), 3-day and 3-4-day ultrafast Kelvin waves in meteor radar observations (Younger and Mitchell, 2006; Lima et al., 2008), 5-day Rossby (W1) and 6-day Kelvin (E1) waves in the SABER-TIMED temperature measurements (Pancheva et al., 2010) and 2.5-4.5-day ultrafast Kelvin waves in both meteor radar and Aura MLS instrument observations (Davis et al., 2012). Particularly through the combined application of meteor radar wind data, MF radar wind data, SABER temperature data and the F-region evening pre-reversal vertical drift measured by Digisonde, Abdu et al. (2015) concluded that both fast Kelvin waves (FK) and ultrafast Kelvin waves (UFK) cause strong modulations in both the evening pre-reversal electric field enhancement and the generation of post-sunset spread-F and plasma bubble irregularities. They also suggested that FK and UFK waves had an important role in the day-to-day variability in the ESF in its occurrence season.

By using various theoretical models, the behavior of Kelvin waves has been successively studied. This includes the dynamo generation of electric fields by Kelvin wave perturbations with the Global-Scale Wave Model (GSWM; Forbes, 2000), ultrafast Kelvin wave modulation of the dynamo with the NCAR Thermosphere, Ionosphere, Mesosphere Electrodynamics General Circulation Model (TIMEGCM; Chang et al., 2010), the calculations of the vertical wavelengths of fast and ultrafast Kelvin waves by using the Kyushu University middle atmosphere general circulation model (Kyushu-GCM; Chen and Miyahara, 2012) and the combined electrodynamical effect of tides and ultrafast Kelvin waves in the MLT region with the E- and F-region ionosphere coupling model (CODB) (Onohara et al., 2013).
In this paper, the characteristics of planetary-wave-type oscillations in the neutral winds, the time rate of change in F-layer virtual heights and ESF occurrence are investigated with an all-sky meteor radar and an ionosonde over two lowlatitude stations at Fuke and Sanya. Over the two stations, ESF irregularities were frequently observed (e.g., Li et al., 2012; Zhu et al., 2013, 2015), which provides us with a good opportunity to study the effects of planetary-wave-type oscillations with different periods on the initiation and development of ESF. By simultaneously employing the wavelet transform and fine spectral analyses to the MLT winds and ionospheric vertical drifts, the preliminary results on the vertical coupling process of these wave oscillations over the Chinese low-latitude region are presented. The overall results are discussed in light of the current understanding of the features of planetary-wave-type oscillations in both vertical drifts of the ionospheric F-layer virtual heights and ESF.

\section{Data and methods}

The observational results of the planetary-wave-type oscillation features presented here were obtained with ionograms recorded by a digital ionosonde (DPS-4D; Lowell Digisonde International) and MLT winds measured with a meteor radar. The ionosonde is installed at Sanya, China $\left(18.4^{\circ} \mathrm{N}\right.$, $109.6^{\circ} \mathrm{E} ; 12.8^{\circ} \mathrm{N}$ dip latitude) and routinely collects ionograms at an interval of $7.5 \mathrm{~min}$ (e.g., Li et al., 2013). The meteor radar is installed at Fuke, China $\left(19.5^{\circ} \mathrm{N}, 109.1^{\circ} \mathrm{E}\right.$; $14^{\circ} \mathrm{N}$ dip latitude) to measure neutral winds (meridional and zonal components) every hour at heights ranging from 70 to $110 \mathrm{~km}$ at $2 \mathrm{~km}$ intervals (e.g., Li et al., 2014). Ionogram and meteor radar wind data obtained in 2013 were used in this 

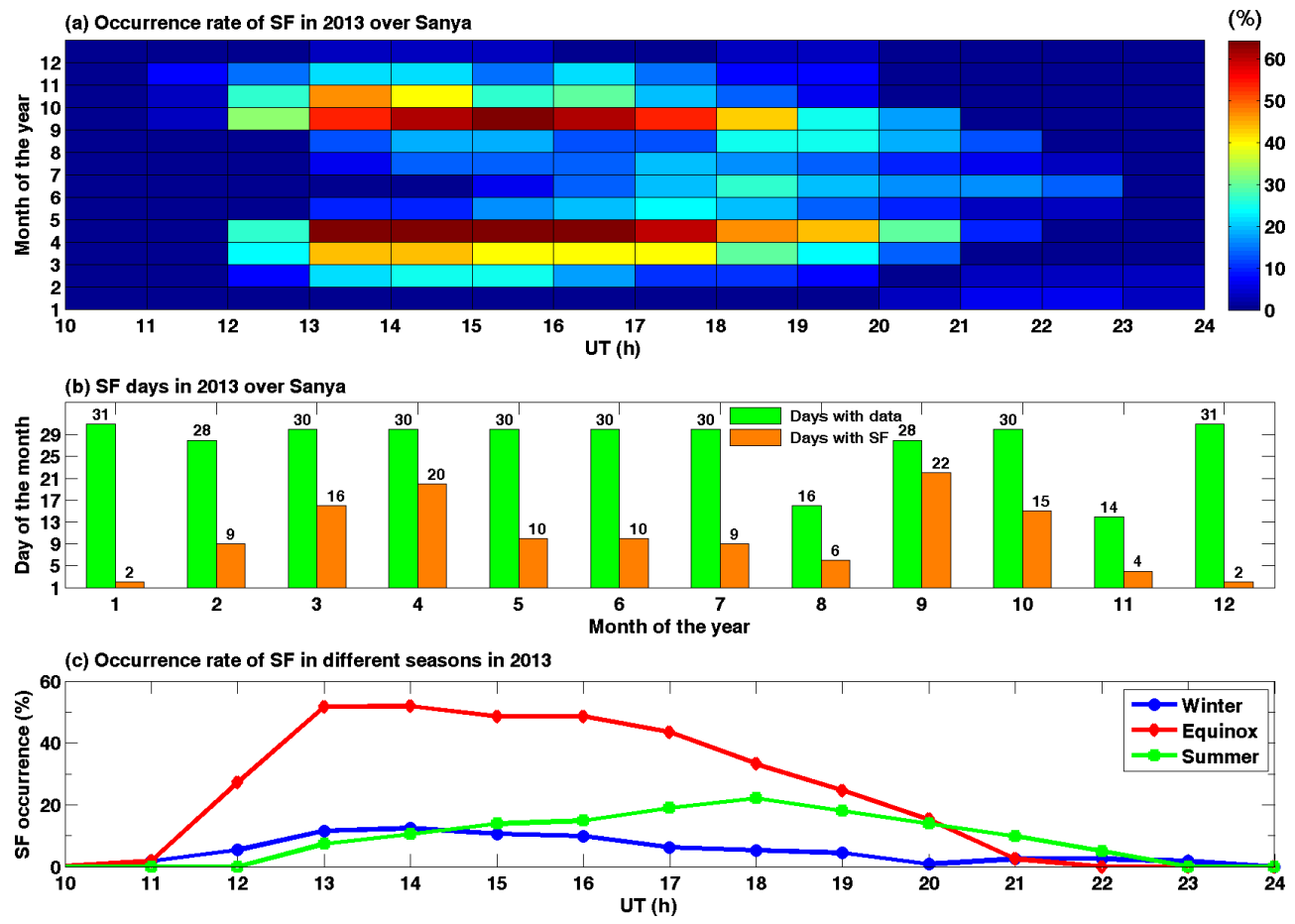

Figure 2. The statistics for SF occurrence in 2013 over Sanya. (a) The monthly occurrence rate of SF versus UT from January to December 2013 at Sanya. (b) The SF occurrence days within the available data for January to December 2013. (c) The variations in the SF occurrence rate with UT in winter, equinox and summer.

study. The ESF events, including the onsets and durations, were manually recognized from the ionograms recorded in 2013, and the virtual heights of the F layer, $h^{\prime} \mathrm{F}$, were manually scaled using SAO Explorer software. The isofrequency plots and the virtual height matrix at the selected frequencies of 3,4,5 and $6 \mathrm{MHz}$ were read from the original RSF (routine scientific format) ionogram files. Figure 1 shows the locations at Sanya and Fuke with the three typical magnetic latitude lines marked by bold lines, along with the $10^{\circ} \mathrm{N}$ dip latitude (blue), the magnetic equator (cyan) and the $10^{\circ} \mathrm{S}$ dip latitude (yellow).

Wavelet analysis has become a favorite tool in geophysics for analyzing nonstationary time series. By decomposing the time series into the time-frequency (period) space, the wavelet transform can determine both the dominant periodicities and their dynamic changes (Torrence and Compo, 1998). In the present analysis, the Morlet wavelet is applied, which consists of a sine wave modulated by a Gaussian envelope. A refinement of this analysis has also been used to investigate concurrent periodicities present in two or more time series. In this case, a cross-wavelet analysis was applied that produced cross-wavelet spectra. The cross-wavelet transform exposes regions with high common power and further reveals features relating to phase information. Specifically, if two series are physically related, a consistent or slowly varying phase lag that can be tested against mechanistic models of the physical process would be expected.
Therefore, the cross-wavelet transform is good for gaining confidence in the cause-effect relationship between time series and testing against mechanistic models of the physical process (e.g., Grinsted et al., 2004). In order to analyze certain details of the selected events, such as the amplitude and significance level for spectral components in a time series, the high-resolution spectral analysis method of the correloperiodogram, as described by Apostolov et al. (1995), was also applied to compute the amplitude spectra. In addition, the Lomb-Scargle periodogram method was used to compute the normalized periodograms because it can handle time series with missing data without the need for interpolation. The technique is based on the least-squares frequency analysis of unequally spaced data and can also return the probability of the frequency spectrum (Lomb, 1976; Scargle, 1982).

\section{Results}

Figure 2 shows the statistics for the spread-F occurrence in 2013 over Sanya. Figure 2a illustrates the monthly occurrence rate of SF versus UT ( $\mathrm{LT}=\mathrm{UT}+7.5 \mathrm{~h}$ ) observed at Sanya from January to December 2013. Each bin is $1 \mathrm{~h} \times 1$ month, and the occurrence rate refers to the percentage of days with available data when SF appears. As shown in Fig. 2a, the SF occurs most frequently in equinoctial months (March, April, September and October) with an 


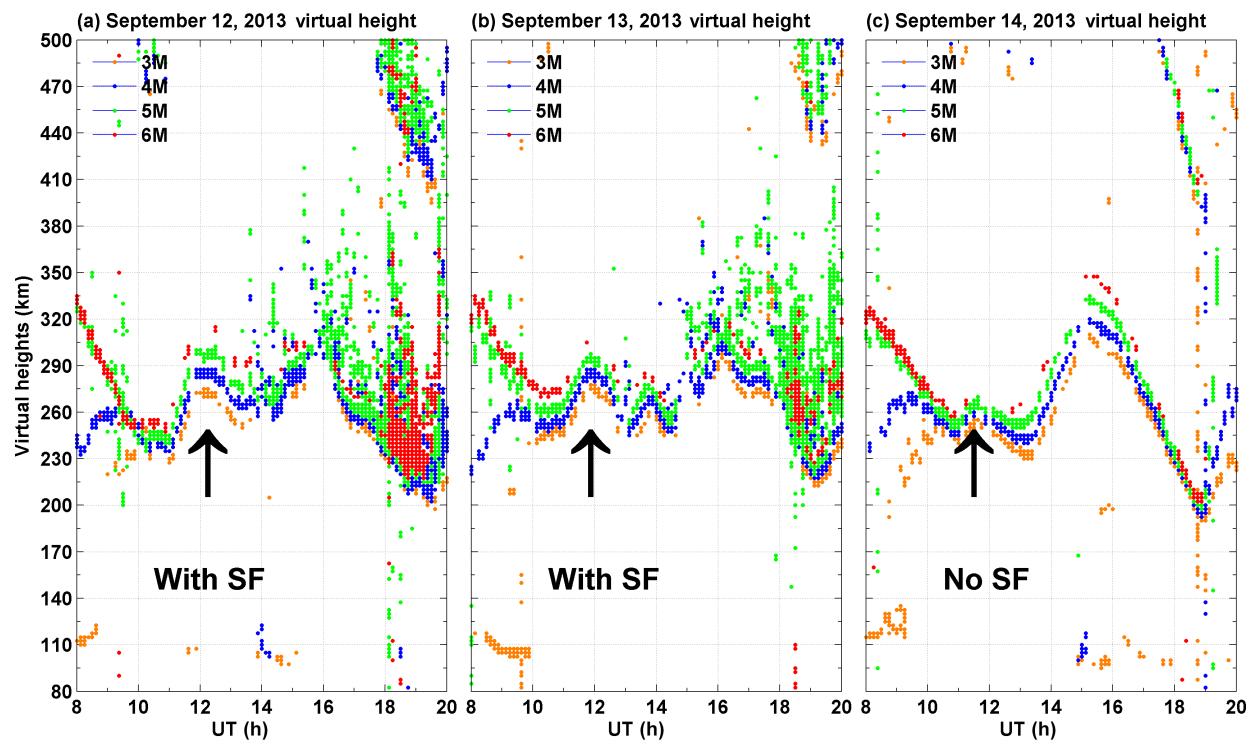

Figure 3. The variations in virtual height at 3, 4, 5 and $6 \mathrm{MHz}$ frequencies (isofrequency plots) from 08:00 to 20:00 UT on 12-14 September 2013 observed by DPS-4D over Sanya with SF (a, b) and with no SF (c). The black bold arrows mark the uplift of the virtual heights by the PRE during post-sunset hours.

average occurrence rate of $27 \%$, followed by summer months (May, June, July and August) with an average occurrence rate of $10 \%$. It is relatively rare in winter months (January, February, November and December) with an average occurrence rate of $6 \%$. Figure $2 b$ demonstrates the comparison of SF days and the days with available data in each month of 2013 over Sanya. As is evident from Fig. 2b, the maximum number of SF occurrence days is in equinoctial months, and the minimum number of SF days is in winter months. Figure 2c displays the occurrence rate of SF versus UT at three times of year. It can be seen from the figure that SF appears most frequently in equinoctial months with a maximum occurrence rate of $52 \%$ at 13:00 UT (20:30 LT) near post-sunset, moderately in summer months with a maximum occurrence rate of $22 \%$ at 18:00 UT (after midnight at 01:30 LT) and sparsely in winter months with a maximum occurrence rate of $12 \%$ at 13:00 UT (20:30 LT) near post-sunset. Another notable feature seen from Fig. 2a and c is that SF starts earlier in equinoctial months than in summer months. It is relevant to mention that the observed spread-F events in equinoctial months in the low latitudes of Southeast Asia are mainly ESF, and their generation is closely related to PRE.

In order to demonstrate the connections between the PRE and SF occurrence during equinoctial months, Fig. 3 reveals several cases in which vertical ionospheric motions play an important role in ESF generation. Figure $3 \mathrm{a}-\mathrm{c}$ show the virtual height variations at $3,4,5$ and $6 \mathrm{MHz}$ frequencies (isofrequency plots) on 3 consecutive days (12-14 September in 2013) from 08:00 UT (15:30 LT) to 20:00 UT (03:30 LT) using RSF ionogram data with a $7.5 \mathrm{~min}$ interval over Sanya. The 3 days (two with SF and one with no SF) are selected to illustrate the correlations between the daily virtual height variations, the day-to-day variations in the electric field PRE and SF occurrence in the SF highoccurrence season of September 2013. It is evident in Fig. 3 on all 3 days that low-frequency echoes (i.e., 3 and $4 \mathrm{MHz}$ ) come from a lower altitude (F-layer bottom) and higherfrequency (i.e., 5 and $6 \mathrm{MHz}$ ) echoes come from a higher altitude (close to the F-layer peak). Figure $3 \mathrm{a}$ and $\mathrm{b}$ illustrate the case of SF and show that there is an obvious uplift of virtual height to about $275 \mathrm{~km}$ in all four frequencies around 12:00 UT (19:30 LT) on these 2 days. About 2 to $3 \mathrm{~h}$ later at 14:00 and 15:00 UT, diffused echoes start to appear in various frequencies. The intensity maximizes at 18:30 and 19:30 UT and lasts until post-midnight at 21:00 and 22:00 UT (04:30 and 05:30 LT), which properly characterizes the signatures of SF occurrence. In contrast, there is only a certain degree of rise in the virtual heights shown in Fig. 3c, but this is only in smaller magnitudes below $250 \mathrm{~km}$; no diffused echoes appear in the next hours. The results show a close correlation between the upward vertical drift and the generation of SF. The second-hop echoes of the transmitted frequencies above $430 \mathrm{~km}$ and E-layer reflection echoes at around $100 \mathrm{~km}$ can also be seen.

For the purpose of studying the effects of the PRE causing F-region uplift in SF occurrence in more detail, the vertical plasma drift velocities are calculated by differentiating the virtual heights of the selected plasma frequencies from ionosonde measurements $\left(\mathrm{d} h^{\prime} \mathrm{F} / \mathrm{d} t\right)$. Although the calculated vertical drifts from time changes in the virtual heights are not thought to be caused completely by electrical fields at the small off-equatorial station of Sanya (possibly also par- 


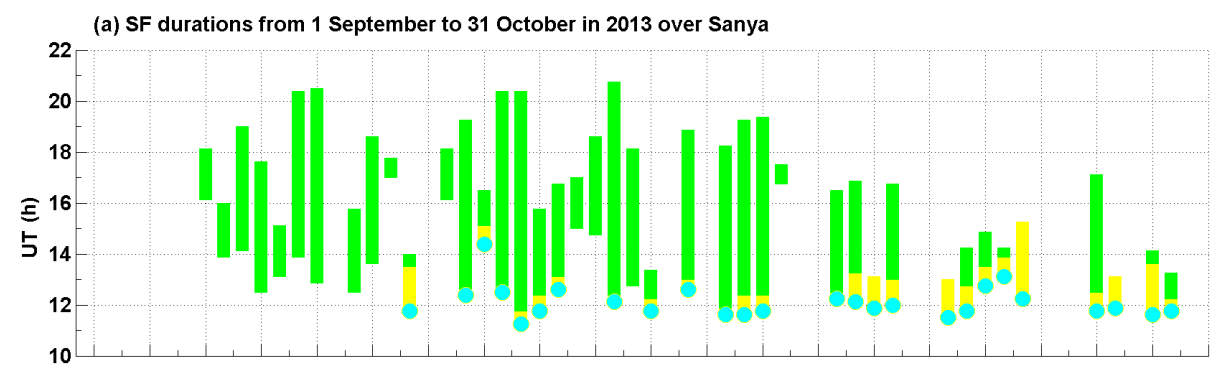

(b) Vz at 12:00-13:00 UT from 1 September to 31 October in 2013 over Sanya

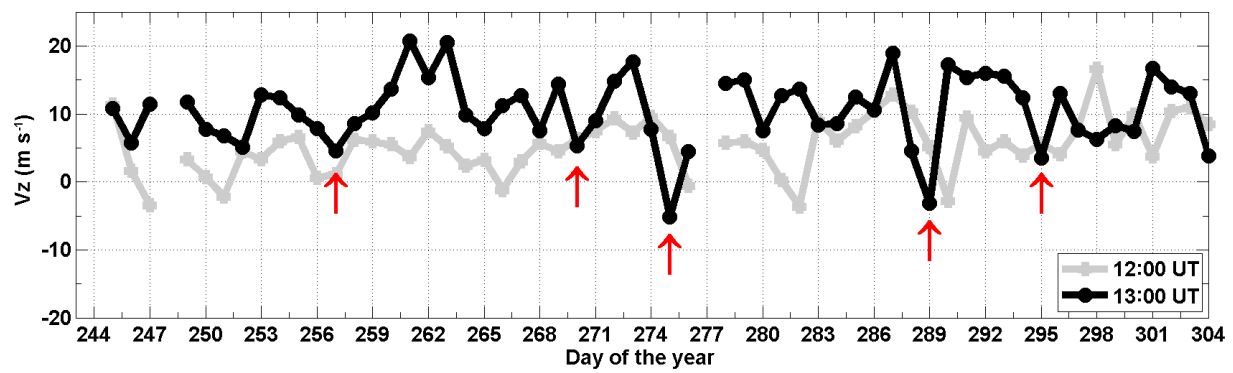

Figure 4. The comparison between the ESF onset and duration and the vertical drift calculated by $\mathrm{d} h^{\prime} \mathrm{F} / \mathrm{d} t$ ( $h^{\prime} \mathrm{F}$ as the virtual height at the selected frequencies of 3, 4, 5 and $6 \mathrm{MHz}$ ) from day 244 to day 304 (1 September to 31 October 2013). (a) The onsets and durations of ESF are denoted by the green bars, while the onsets and durations of ST are denoted by the cyan dots and the yellow bars, respectively. (b) The computed vertical drift at 12:00 UT (the thin bold lines) and 13:00 UT (the thick bold lines) around post-sunset hours.

tially by neutral winds), the ones during evening hours when the $\mathrm{F}$ layer rises up due to the pre-reversal enhancement in the zonal electrical field may be regarded as good indicators of the vertical plasma drifts of the F layer. Many researchers have provided useful evidence on this issue. It has been shown from theoretical computations (Bittencourt and Abdu, 1981) and by experimental verification (Scali et al., 1995) that these velocities are identical to the vertical plasma drift velocities for heights near and above $300 \mathrm{~km}$ at which the recombination effects become negligible. Experiments were also carried out by comparing such velocities with the drift velocities acquired by the Digisonde drift measurements (Abdu et al., 2006d) with the DDA (Digisonde drift analysis) model designed by Reinisch et al. (2004) and incoherent scatter radar (ISR) measurements (Bertoni et al., 2006). By using this technique, the vertical drift velocities versus UT over the three COPEX (conjugate point equatorial experiment) sites were obtained to successfully investigate the related electrodynamic processes on spread-F development conditions and their day-to-day variability (Abdu et al., 2009b). Frequencies of $3,4,5$ and $6 \mathrm{MHz}$, which are basically below $f o \mathrm{~F}_{2}$, are selected for calculating the vertical drift velocities (denoted by $\mathrm{Vz}$ in Fig. 4b) during evening and post-sunset hours when the F layer rises to nearly $300 \mathrm{~km}$ due to electrical field PRE. These are compared with the SF occurrence statistics (the onsets and durations for SF in Fig. 4a) on day 244 to day 304 (1 September to 31 October 2013) during the SF higher-occurrence epoch. The onsets and durations of the satellite traces, which are usually present when F-layer plasma density is modulated in the zonal direction so that radio waves can be reflected back in several directions with perpendicularity between the radio line-of-sight and the layered $\mathrm{F}$ region (e.g., Abdu et al., 1981; Tsunoda, 2007; Li et al., 2012), are also marked with cyan solid dots and vertical bold yellow bars, respectively in Fig. 4a. In Fig. 4b, the instantaneous vertical drifts $(\mathrm{Vz})$ are denoted by the black solid dots corresponding to the same day shown in Fig. 4a, and the thin and thick bold lines denote the $\mathrm{Vz}$ calculated at 12:00 and 13:00 UT, respectively, both at post-sunset hours. As is evident from Fig. $4 b$, the variation trends at the two moments are basically consistent; thus this also provides supporting evidence for the presence of certain period wave oscillations. By comparing Fig. 4a with Fig. 4b, it can be found that the magnitude and direction of $\mathrm{Vz}$ has a significant control on SF occurrence. For example, during the four downward peaks identified by the red arrows, the vertical drift velocities are small enough and below a certain threshold value; these correspond to day 257, day 275, day 289 and day 295, on which SF basically does not appear. However, there is an exception: on day 270 when the vertical drift velocity is at its local minimum, SF appears. This suggests that this spread-F event might not be caused locally. Another obvious feature seen in Fig. 4 is that SF definitely occurs when the vertical drift velocity is upward and its value is larger than $15 \mathrm{~m} \mathrm{~s}^{-1}$. In previous studies, the threshold value of the vertical drift velocity for SF occurrence was $20 \mathrm{~m} \mathrm{~s}^{-1}$ by Abdu et al. (1983) over the magnetic equatorial station at Fortaleza, Brazil ( $4^{\circ} \mathrm{S}, 38^{\circ} \mathrm{W} ; 1.8^{\circ} \mathrm{S}$ dip latitude) and $5-10 \mathrm{~m} \mathrm{~s}^{-1}$ by Fejer et al. (1999) over the Jicamarca Radio Observatory in Peru $\left(12^{\circ} \mathrm{S}, 76.9^{\circ} \mathrm{W} ; 1^{\circ} \mathrm{N}\right.$ dip latitude). In fact, because 
Sanya is in the low-latitude region, according to Abdu et al. (2006b), the threshold value of the vertical drift velocity $\left(15 \mathrm{~m} \mathrm{~s}^{-1}\right)$ should be larger than that $\left(20 \mathrm{~m} \mathrm{~s}^{-1}\right)$ over the magnetic equatorial station at Fortaleza (Abdu et al., 1983). The cause of this deviation may be that only the influence of the electric field is considered in calculating the vertical drift velocity from the $\mathrm{d} h^{\prime} \mathrm{F} / \mathrm{d} t$, while the effect of the background winds is ignored, especially in low-latitude regions.

To investigate the possible correlation between SF initiation and the vertical drift of the $\mathrm{F}$ region via wave oscillations, cross-wavelet transform is implemented between SF onsets and the vertical drifts from 12:00 to 14:00 UT (19:30-21:30 LT) around post-sunset hours. Figure 5 shows the cross-wavelet power spectrum and the phase difference between SF onsets (including all ESF days denoted by the green bars in Fig. 4a) and the vertical drifts at 12:00 (panel a), 13:00 (panel b) and 14:00 UT (panel c) during day 244-304 (1 September to 31 October) in 2013. The black border lines (parabolic curves opening downward) denote the cone of influence (COI), defined as the region of the wavelet power spectrum in which edge effects become important caused by the beginning and end of the data sets. The phase differences are shown as arrows (with in-phase pointing to the right, antiphase pointing to the left and Vz leading SF onset by $90^{\circ}$ pointing vertically upwards). As illustrated in Fig. 5, there are significant common wave oscillations with 3-7day periods existing concurrently in the SF onsets and the vertical drifts at the three moments (presented in Fig. 5a, $\mathrm{b}$ and c) with larger power intensities and a $95 \%$ confidence level (surrounded by the bold black lines). This suggests that planetary-wave-type oscillations with 3-7-day periods exert an important excitation on SF initiation. Meanwhile, the phases of the 7-day common waves are mostly antiphase, while those of the 3-day common waves are basically in-phase. Specific to this situation, antiphase means that SF starts earlier (numerically small) under the condition of larger vertical drift velocity (numerically large), and this instance is highly consistent with that presented in Fig. 4. Moreover, this also confirms that the 7-day waves play a dominant role in the SF events compared with the 3-day waves, which could in turn be verified in terms of a larger (smaller) power spectrum corresponding to the 7-day (3-day) waves in the amplitude of the cross-wavelet power spectrum. The causes of the phenomenon will be described later in the appropriate section.

For studying the vertical coupling process of planetarywave-type oscillations from the MLT region up to the ionosphere, the zonal wind at $96 \mathrm{~km}$ at the MLT height and the vertical drift of the virtual height at the ionospheric height are simultaneously subjected to wavelet transform. Figure 6 shows the comparison of the wavelet power spectra between the zonal wind at $96 \mathrm{~km}$ and the instant vertical drift at 3-6 MHz at 13:00 UT (20:30 LT) during the SF occurrence peak from day 244 to day 304 in 2013. It is clear that there are 3-day and 7-day planetary-wave-type oscillations in both the lower atmosphere and the ionosphere; with increasing height, wave amplification and filtering are also observed. For the 7-day waves marked with the white arrows in the two different height regions (one on day 274 in Fig. $6 \mathrm{~b}$ and another on day 280 in Fig. 6a), an approximate 6-day delay was observed between them. The 3-day wave centered in the lower panel was on day 257 and that in the upper panel was on day 262; thus an approximate 5-day delay was observed between them. Furthermore, the 3-day waves are gradually amplified with increasing height but with a relatively weaker intensity compared with the 7-day waves. This result is consistent with the result shown in Fig. 5 that the 7-day waves play a dominant role at ionospheric heights.

To further determine the exact period of planetary-wavetype oscillations in both the lower atmosphere and the ionosphere, a Lomb-Scargle periodogram analysis (aforementioned) is applied to the zonal winds in the MLT region and the vertical drifts of the virtual heights in the ionosphere. Figure 7 shows the amplitude spectrum of the daily averaged zonal winds at heights of 88 to $98 \mathrm{~km}$ in the lower atmosphere (the lower panel) and the vertical drifts from 10:00 UT (17:30 LT) to $15: 00 \mathrm{UT}(22: 30 \mathrm{LT})$ at the ionospheric height from 1 September to 31 October 2013 over two Chinese lowlatitude stations at Fuke and Sanya. The 7-day waves are the strongest on the amplitude spectrum in the lower atmosphere, while at the higher heights of the ionosphere the waves with shorter periods, such as the 4.8-day period waves (considered quasi-3-day waves), gradually occupy a dominant position along the frequency axis. However, the 7-day waves are still an important frequency component in the amplitude spectrum in both the lower atmosphere and the ionosphere. This suggests that the waves with the shorter periods are increasingly amplified with increasing heights, while the waves with the longest periods, such as the 7-day waves, are partially decomposed into waves with shorter periods like the 5-day and the 3-day waves. It should be noted from Fig. 7a that the amplitude spectra of the vertical drift velocities from 10:00 to 15:00 UT also present a larger dispersion, which may be due to the larger dispersions for extracting the virtual heights from GRM ionogram files; however, this does not affect the manifestation of the extracted fluctuation components.

To depict the characteristics of vertical interactions from MLT regions to the ionosphere in detail, we select the zonal wind at $94 \mathrm{~km}$ in the MLT area and the vertical drift of the Flayer virtual height in the ionosphere at 13:00 UT, when the spread-F occurrence rate is at its maximum, to be analyzed with the correloperiodogram algorithm for a fine spectrum analysis. Figure 8 shows the correloperiodogram amplitude spectra of the zonal wind at $94 \mathrm{~km}$ (the solid line) and the vertical drift of the virtual height at 13:00 UT (the dotted line). As is evident from the figure, a number of similarities exist between the zonal wind and the vertical drift of the virtual height at two different heights. Although their amplitude spectral intensities are not on the same level (in order to increase comparability in the same panel, a factor of 2.78 is 


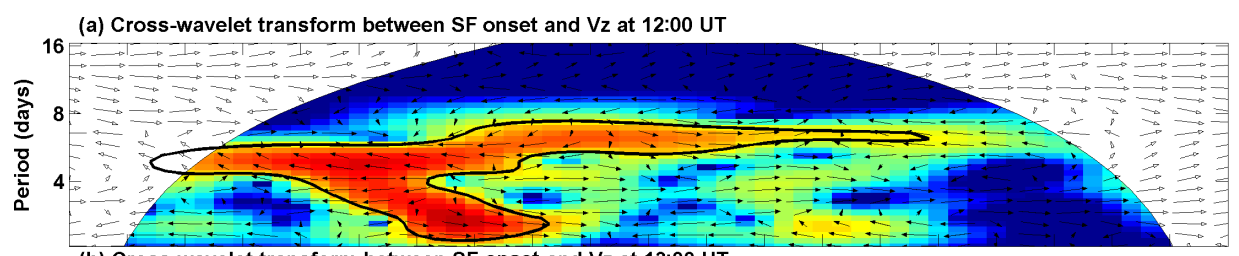

(b) Cross-wavelet transform between SF onset and Vz at 13:00 UT

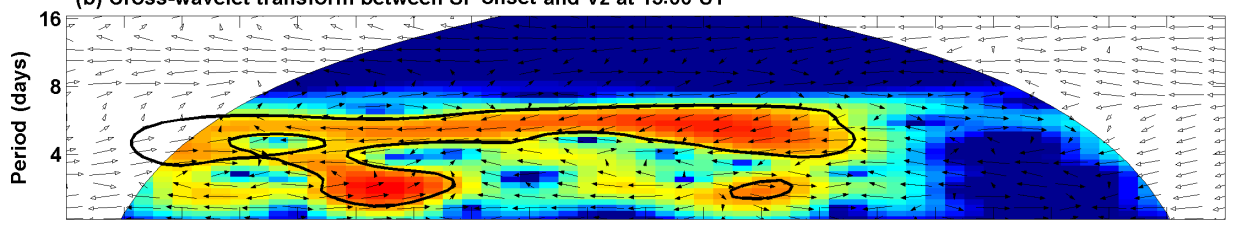

(c) Cross-wavelet transform between SF onset and Vz at 14:00 UT

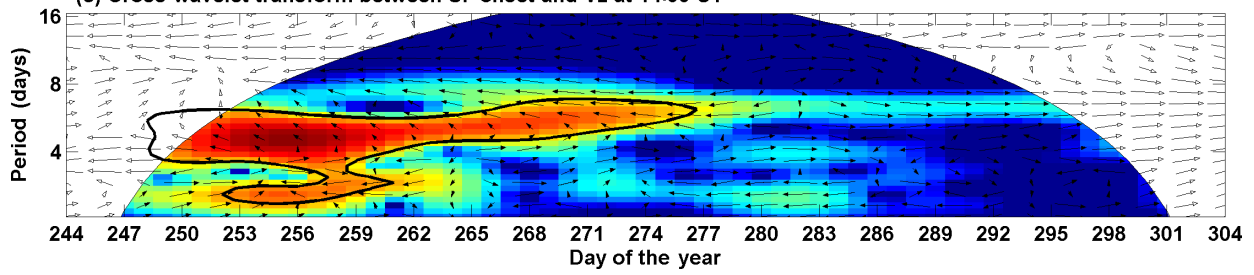

Figure 5. The cross-wavelet transform between the SF onsets and the vertical drifts (Vz) at 12:00 UT (a), 13:00 UT (b) and 14:00 UT (c). The black border lines (parabolic curves opening downward) denote the cone of influence (COI) for the beginning and end of the data sets. The short black arrows denote the phase difference between the two time series with in-phase pointing right, antiphase pointing left and $\mathrm{Vz}$ leading SF onset by $90^{\circ}$ pointing vertically upwards.

(a) Vz at 13:00 UT over Sanya

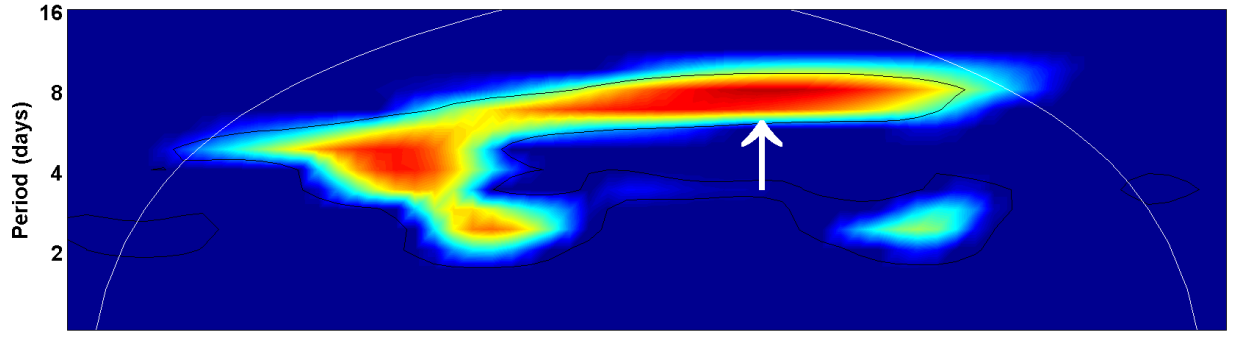

(b) Zonal wind at $96 \mathrm{~km}$ over Fuke

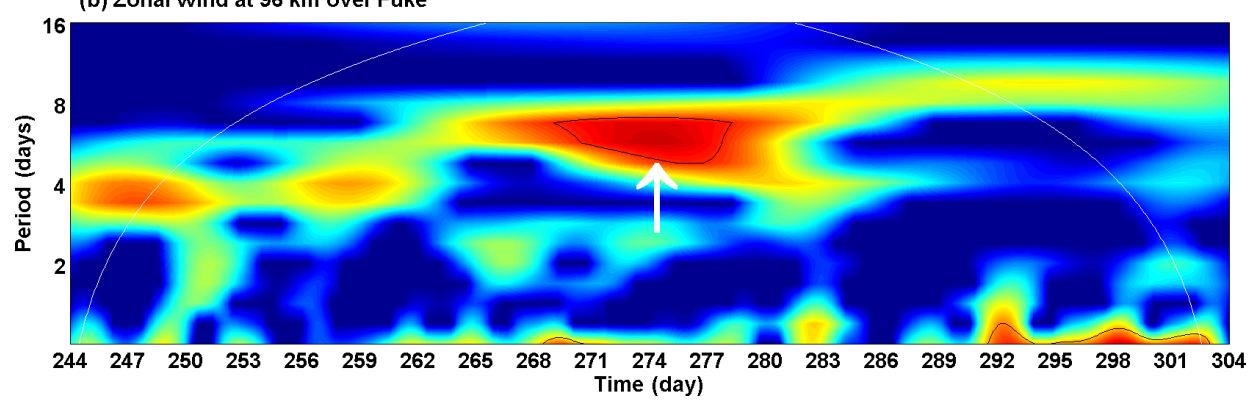

Figure 6. The comparison of the wavelet power spectra for the zonal wind at $96 \mathrm{~km}$ at the MLT height over Fuke and the instant vertical drift at 3-6 MHz at 13:00 UT at the ionospheric height over Sanya from day 244 (1 September) to day 304 (31 October) in 2013 . The white parabolic arch denotes the cone of the influence (COI). (a) The wavelet power spectrum of the vertical drift at 13:00 UT. (b) The wavelet power spectrum of the zonal wind at $96 \mathrm{~km}$ in the lower atmosphere.

multiplied by the vertical drift curve marked with an arrow in the figure), the shapes of the amplitude spectra exhibit very similar characteristics. The quasi-7-day waves (6.5 days for the zonal wind and 7.8 days for the vertical drift) occupy the maximum spectral intensity along all spectral ranges. For the 3-day waves, at lower heights the spectral peak is on the third level, and at ionospheric heights the spectral peak moves to the second level. This supports the results from Fig. 7b that the 3-day waves are successively amplified during upward propagation, and the 7-day waves are dominant within 20- 


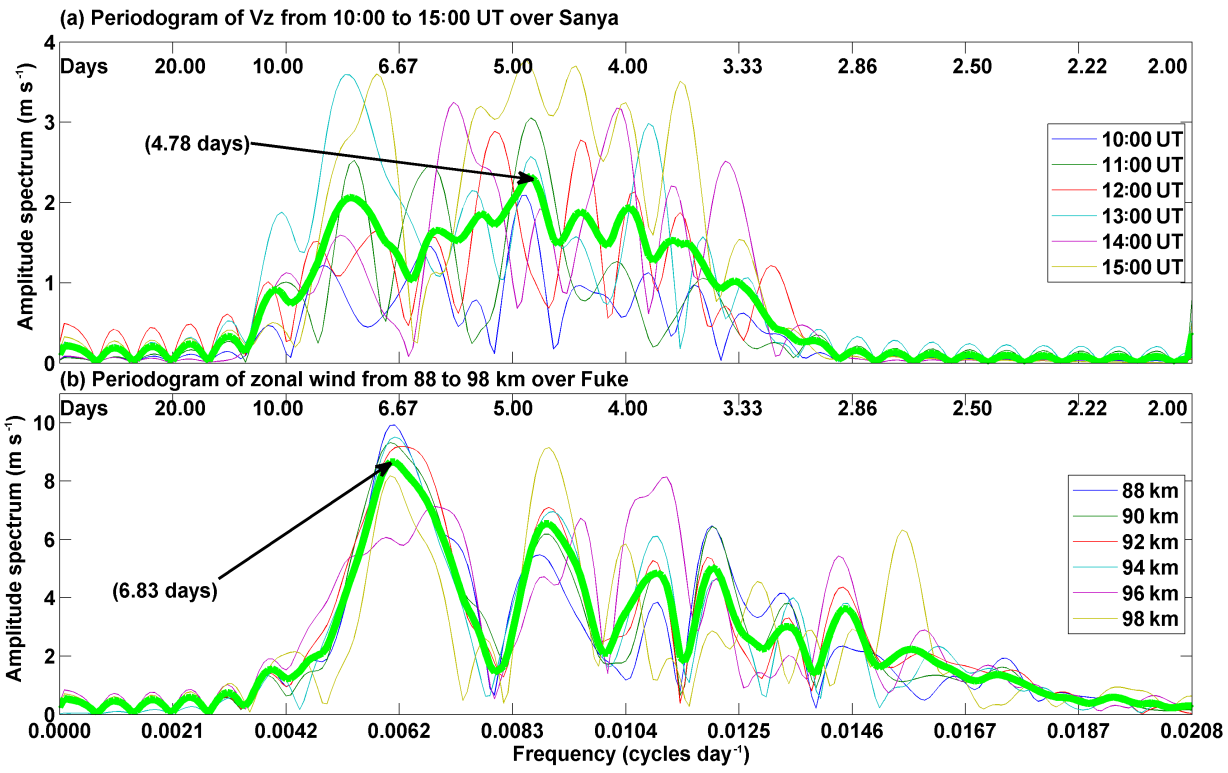

Figure 7. The Lomb-Scargle amplitude spectrum of the vertical drifts in the ionosphere (a) and that of the zonal winds at $88-98 \mathrm{~km}$ in the MLT region (b). The thin lines with different colors denote the amplitude spectrum lines from 10:00 to 15:00 UT (the upper panel) and from 88 to $98 \mathrm{~km}$ (the lower panel). The thick green line denotes the mean spectrum in the two panels.

day periods of planetary-wave-type oscillations, persisting as basically constant in both the lower atmosphere and the ionosphere.

\section{Discussion}

We have presented observational results to indicate the presence of vertical coupling processes involving planetarywave-type oscillations in MLT and the ionosphere in a lowlatitude atmosphere-ionosphere system. However, the quasiperiod oscillations in the MLT region and the ionosphere are also likely to be caused by geomagnetic activity or solar activity above the atmosphere-ionosphere system. To examine the possibility of any influence on the observed PRE modulation and ESF from geomagnetic activity or solar activity, the auroral activity index (AE) and the solar flux index F10.7 are also implemented by wavelet transform (not shown here). The results reveal that any contribution from solar activity or geomagnetic activity is completely ruled out, but there is a 9-day wave oscillation in the $\mathrm{AE}$ wavelet power spectrum. Lei et al. (2008) have suggested that the 9-day periodicity in geomagnetic activity and thermospheric densities could be caused by a rotating triad of coronal holes corresponding to the third harmonic of the quasi-periodic solar rotation frequency. Significant amplitudes of 3-day and 7-day planetarywave-type oscillations are commonly present in MLT regions and at ionospheric heights as shown in Fig. 5. The periodicities are in good agreement with those of the widely observed planetary-wave-scale oscillations in both the MLT and the ionosphere (see e.g., Pancheva et al., 2003; Takahashi et al.,
2005). Further, the evening F-layer uplift due to the PRE, as presented in Fig. 3, is believed to be the main cause of the generation of post-sunset spread-F and plasma bubble irregularities (see e.g., Abdu et al., 2003). It can be clearly seen from Fig. 4 that vertical drift velocities have a significant control on the onsets and durations of SF, specifically larger downward vertical drift velocities corresponding to either no SF or a later onset with a short duration. Although there are some important exceptions that can be seen in Fig. 4, it can be confirmed that planetary-wave-type oscillations are present in the evening PRE expressed by the vertical drifts, which in turn control the formation and development of spread F. Moreover, the experimental observations and theoretical calculations do not support the direct penetration of planetary-wave-type oscillations into the ionospheric dynamo regions (Forbes, 1996). However, the generation of the PRE through E- and F-region electrodynamical coupling processes revealed that the effects of planetary-wave-type oscillations reaching at least the E-layer heights were the main cause of the oscillations observed in the peak amplitude of the PRE (Abdu et al., 2006c). Explanations for these results are presented in the following.

The thermospheric zonal winds (eastward in the evening) yield a vertical electric field (downward) in the $\mathrm{F}$ region that results in the development of the PRE. This was first proposed by Rishbeth (1971) and then modeled in theory by Heelis et al. (1974). The produced vertical electric field $E_{z}$ is presented in Eq. (1) following Abdu et al. (2003): 


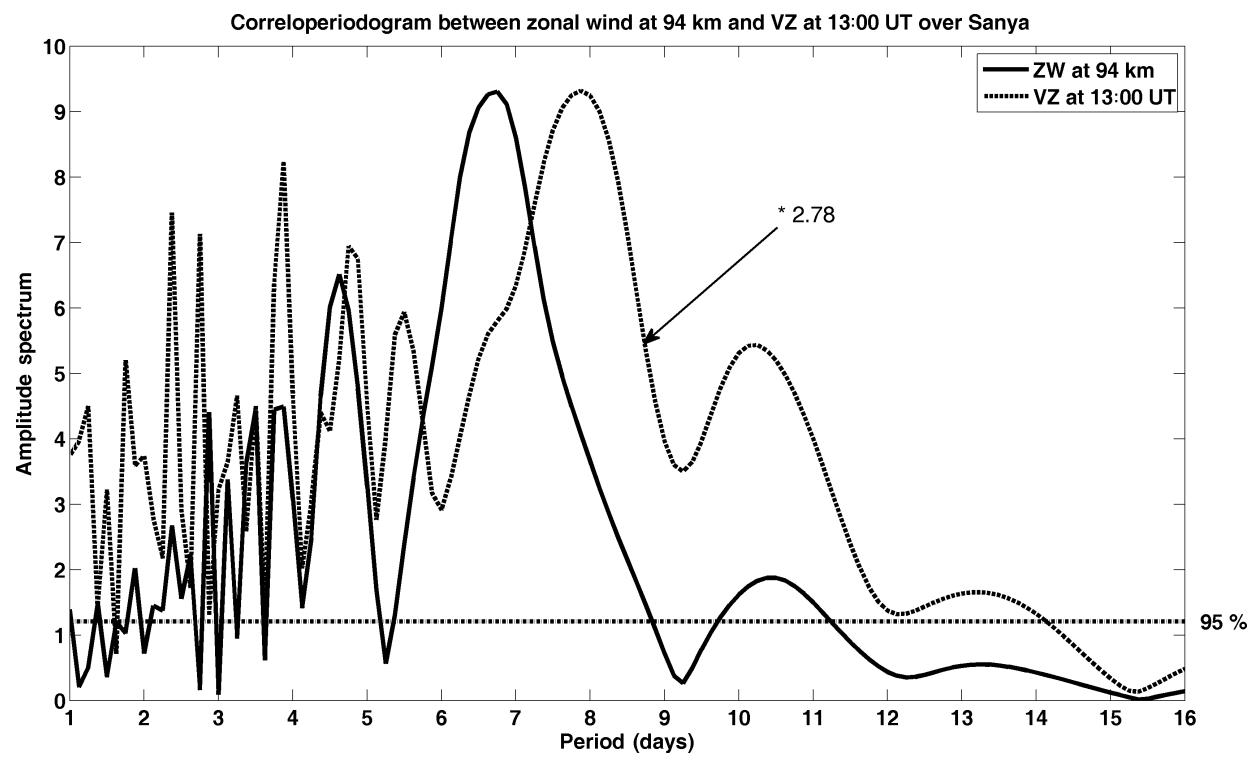

Figure 8. The correloperiodogram amplitude spectra of the zonal wind at $94 \mathrm{~km}$ (the solid line) over Fuke and the vertical drift of the F-layer virtual height at 13:00 UT (the dotted line) over Sanya. The horizontal dotted lines denote the $95 \%$ confidence level.

$E_{z}=U_{y} \times B_{0}\left[\sum_{S} /\left(\sum_{L}+\sum_{S}\right)\right]$,

where $U_{y}$ is the thermospheric zonal wind, $B_{0}$ is the geomagnetic field intensity, $\sum_{S}$ is the Pedersen conductivity integrated along the parts of a field line in the F region (regarded as the source region) and $\sum_{L}$ is integrated along the same field line for the parts extending into the conjugate $\mathrm{E}$ regions (regarded as the load region). It can be easily understood from Eq. (1) that during the daytime when the load region conductivity $\sum_{L}$ (of the E region) is large $\left(\sum_{L} \gg \sum_{S}\right), E_{z}$ tends to be zero as expected. At post-sunset hours, $\sum_{L}$ decays faster than $\sum_{S}$, thus leading to the development of a vertical electric field with an intensity that increases towards the nightside (namely, across the terminator). The application of the curl-free condition to such an electric field variation could contribute to the enhanced evening zonal electric field, the PRE. It can also be noted in Eq. (1) that the magnitudes of the zonal winds along with those of the conductivity longitudinal gradients across the terminator are able to control the intensity of the PRE (Abdu et al., 2003). Therefore, planetary-wave-type oscillations observed in the PRE (see Figs. 5 and 6) could be catalyzed by such oscillations, either in the magnitudes of the thermospheric zonal winds or in the intensities of the conductivity longitudinal gradients. According to the one-dimensional results of height-integrated Pedersen conductivity as a function of time for zonal wind amplitudes in Abdu et al. (2003), it is evident that the integrated conductivity longitudinal gradient increases significantly with increases in the zonal wind amplitudes in the $\mathrm{E}$ region. Underlying such an interpretation, it is likely that the amplitudes of the PRE, which rely on the longitudinal gradi- ent of the E-layer-integrated conductivity, could go through oscillations due to the corresponding oscillations in the amplitude of the E-layer zonal winds; these could in turn be modulated by planetary-wave-type oscillations by means of nonlinear interactions.

\section{Conclusions}

We have observed 3-7-day planetary-wave-type oscillations simultaneously in the zonal winds routinely monitored by the meteor radar in the MLT region and the time rate of change in $h^{\prime} \mathrm{F}$ collected by the DPS-4D ionosonde at ionospheric heights during an SF high-occurrence epoch (1 September to 31 October) in 2013 over two Chinese low-latitude stations. As 2013 is close to the solar maximum, it is referred to here as a solar "mini-max" year. We analyzed the occurrence rate of spread $\mathrm{F}$ for 2013 by manually identifying ionograms, investigating the features of dominant planetary-wave-type oscillations with a series of spectrum analyses in the MLT region and at ionospheric heights and studying the vertical coupling process involving planetary-wave-type oscillations during their upward propagation and their possible effects as a seeding mechanism for SF initiation and development. The main conclusions are summarized as follows.

1. Common wave oscillations with periods of 3-7 days are observed in simultaneous measurements of MLT winds and time rate of change in ionospheric virtual heights. In the MLT region with the correloperiodogram spectrum analysis of the zonal winds, the 7-day waves have the strongest intensity, much larger than that of the 3day waves, and a similar structure from 88 to $98 \mathrm{~km}$. At 
ionospheric heights, however, with the Lomb-Scargle periodogram analysis of the vertical drifts of the F-layer virtual heights, the 3-day waves possess a larger intensity than that in the lower atmosphere. This suggests that the 7-day waves continuously present with a comparable intensity in both the MLT regions and in the ionospheric region, while the 3-day waves are gradually amplified with increasing heights.

2. Spread $F$ occurred most frequently in equinoctial months over the Chinese low-latitude station at Sanya in the 2013 solar mini-max year. During SF highoccurrence epochs, the vertical drifts of the F-layer virtual heights as typical indicators of the F-layer uplift due to PRE are jointly investigated with SF occurrence statistics. Spread F appears to be substantially accompanied by a rise in the virtual height for an approximate $30 \mathrm{~km}$ about $2 \mathrm{~h}$ before SF occurrence. Moreover, the 7-day waves are basically antiphase with a crosswavelet transform between the SF onsets and the vertical drifts, implying that spread F starts earlier and is usually longer in duration when the intensities of the 7day upward waves are larger; they may therefore play a major role in SF initiation and development compared with the 3-day waves.

3. Due to the 7-day wave oscillation power displacement from day 274 at the MLT height to day 280 at ionospheric heights shown in Fig. 6, an approximate 6-day delay is estimated for the 7-day wave oscillation propagating from the lower atmosphere to the ionosphere. Similarly for the 3-day wave oscillation, the estimation of the delay is about 5 days. As Takahashi et al. (2006) have pointed out, the global-scale planetary-wave-type oscillations could drive electric currents and plasma drifts, and the 3-7-day waves could also propagate upwards from the stratosphere to the mesosphere and the lower thermosphere. They could also interact with the ionosphere, modulating E-region conductivity and the F-region dynamo. Therefore, through this joint research on spread-F events, it can be inferred that this mechanism is important in relation to spread-F formation and its day-to-day variability through planetary-wave-type oscillations.

Data availability. The data used in this paper can be obtained on request from the corresponding author.

Competing interests. The authors declare that they have no conflict of interest.

Acknowledgements. We acknowledge the use of the ionogram data from the Beijing National Observatory of Space Environment and the meteor wind data from the Chinese Meridian Project. This work is supported by the National Natural Science Foundation of China (41474135, 41474134, 41127003).

The topical editor, Steve Milan, thanks two anonymous referees for help in evaluating this paper.

\section{References}

Abdu, M. A.: Equatorial ionosphere-thermosphere system: electrodynamics and irregularities, Adv. Space Res., 35, 771-787, 2005.

Abdu, M. A. and Brum, C. G. M.: Electrodynamics of the vertical coupling processes in the atmosphere-ionosphere system of the low latitude region, Earth Planets Space., 61, 385-395, 2009.

Abdu, M. A., Bittencout, J. A., and Batista, I. S.: Some characteristics of spread $F$ at magnetic equatorial station Fortaleza, J. Geophys. Res., 86, 6836-6842, 1981.

Abdu, M. A., Medeiros, R. T., Bittencourt, J. A., and Batista, I. S.: Vertical ionization drift velocities and range type spread $F$ in the evening equatorial ionosphere, J. Geophys. Res., 88, 399-402, 1983.

Abdu, M. A., MacDougall, J. W., Batista, I. S., Sobral, J. H. A., and Jayachandran, P. T.: Equatorial evening prereversal electric field enhancement and sporadic E layer disruption: a manifestation of $\mathrm{E}$ and F region coupling, J. Geophys. Res., 108, 1254, https://doi.org/10.1029/2002JA009285, 2003.

Abdu, M. A., Ramkumar, T. K., Batista, I. S., Brum, C. G. M., Takahashi, H., Reinisch, B. W., and Sobral, J. H. A.: Planetary wave signatures in the equatorial atmosphere-ionosphere system, and mesospheire - E- and F region coupling, J. Atmos. Terr. Phys., 68, 509-522, 2006a.

Abdu, M. A., Iyer, K. N., de Medeiros, R. T., Batista, I. S., and Sobral, J. H. A.: Thermospheric meridional wind control of equatorial spread $\mathrm{F}$ and evening prereversal electric field, Geophys. Res. Lett., 33, L07106, https://doi.org/10.1029/2005GL024835, $2006 b$.

Abdu, M. A., Batista, P. P., Batista, I. S., Brum, C. G. M., Carrasco, A., and Reinisch, B. W.: Planetary wave oscillations in mesospheric winds, equatorial evening prereversal electric field and spread F, Geophys. Res. Lett., 33, L07107, 1-4, 2006 c.

Abdu, M. A., Batista, I. S., Reinisch, B. W., Sobral, J. H. A., and Carrasco, A. J.: Equatorial $F$ region evening vertical drift during southern winter months: A comparison of observational data with IRI descriptions, Adv. Space Res., 37, 1007-1017, https://doi.org/10.1016/j.asr.2005.06.074, 2006d.

Abdu, M. A., Batista, I. S., Reinisch, B. W., de Souza, J. R., Sobral, J. H. A., Pedersen, T. R.A., Medeiros, F., Schuch, N. J., de Paula, E. R., and Groves, K. M.: Conjugate Point Equatorial Experiment (COPEX) campaign in Brazil: Electrodynamics highlights on spread $\mathrm{F}$ development conditions and day-to-day variability, J. Geophys. Res., 114, A04308, https://doi.org/10.1029/2008JA013749, 2009.

Abdu, M. A., Brum, C. G. M., Batista, P. P., Gurubaran, S., and Pancheva, D.: Fast and ultrafast Kelvin wave modulations of the equatorial evening F region vertical drift and Spread F development, Earth Planets Space, 67, https://doi.org/10.1186/s40623014-0143-5, 2015. 
Apostolov, E. M., Altadill, D., and Alberca, L.: Characteristics of quasi-2-day oscillations in the $f o \mathrm{~F} 2$ at northern middle latitudes, J. Geophy. Res., 100, 12163-12171, 1995.

Beard, A. G., Mitchell, N. J., Williams, P. J. S., and Kunitake, M.: Non-linear interactions between tides and planetary waves resulting in periodic tidal variability, J. Atmos. Sol.-Terr. Phy., 61, 363-376, 1999.

Bertoni, F., Batista, I. S., Abdu, M. A., Reinisch, B. W., and Kherani, E. A.: A comparison of ionospheric vertical drift velocities measured by Digisonde and incoherent scatter radar at the magnetic equator, J. Atmos. Sol.-Terr. Phy., 68, 1851-1852, 2006.

Bertoni, F. C. P., Sahai, Y., Raulin, J. P., Fagundes, P. R., Pillat, V. G., Gimenez de Castro, C. G., and Lima, W. L. C.: Equatorial spread-F occurrence observed at two near equatorial stations in the Brazilian sector and its occurrence modulated by planetary waves, J. Atmos. Sol.-Terr. Phy., 73, 457-463, 2011.

Bittencourt, J. A. and Abdu, M. A.: A theoretical comparison between apparent and real vertical ionization drift velocities in the equatorial F region, J. Geophys. Res., 86, 2451-2455, https://doi.org/10.1029/JA086iA04p02451, 1981.

Booker, H. G. and Wells, H. W.: Scattering of radio waves by the F-region of the ionosphere, J. Geophys. Res., 43, 249-256, 1938.

Chang, L. C., Palo, S. E., Liu, H. L., Fang, T. W., and Lin, C. S.: Response of the thermosphere and ionosphere to an ultra fast Kelvin wave, J. Geophys. Res., 115, A00G04, https://doi.org/10.1029/2010JA015453, 2010.

Chang, L. C., Liu, J. Y., and Palo, S. E.: Propagating planetary wave coupling in SABER MLT temperatures and GPS TEC during the 2005/2006 austral summer, J. Geophys. Res., 116, A10324, https://doi.org/10.1029/2011JA016687, 2011.

Chen, Y. W. and Miyahara, S.: Analysis of fast and ultrafast Kelvin waves simulated by the Kyushu-GCM, J. Atmos. Sol.-Terr. Phy., 80, 1-11, 2012.

Davis, R. N., Chen, Y.-W., Miyahara, S., and Mitchell, N. J.: The climatology, propagation and excitation of ultra-fast Kelvin waves as observed by meteor radar, Aura MLS, TRMM and in the Kyushu-GCM, Atmos. Chem. Phys., 12, 1865-1879, https://doi.org/10.5194/acp-12-1865-2012, 2012.

de Abreu, A. J., Fagundes, P. R., Bolzan, M. J. A., de Jesus, R., Pillat, V. G., Abalde, J. R., and Lima, W. L. C.: The role of the traveling planetary wave ionospheric disturbances on the equatorial $\mathrm{F}$ region post-sunset height rise during the last extreme low solar activity and comparison with high solar activity, J. Atmos. Sol.-Terr. Phy., 113, 47-57, 2014a.

de Abreu, A. J., Fagundes, P. R., Bolzan, M. J. A., Gende, M., Brunini, C., de Jesus, R., Pillat, V. G., Abalde, J. R., and Lima, W. L. C.: Traveling planetary wave ionospheric disturbances and their role in the generation of equatorial spread-F and GPS phase fluctuations during the last extreme low solar activity and comparison with high solar activity, J. Atmos. Sol.-Terr. Phy., 117, 7-19, 2014b.

Fagundes, P. R., Pillat, V. G., Bolzan, M. J. A., Sahai, Y., BeckerGuedes, F., Abalde, J. R., Aranha, S. L., and Bittencourt, J. A.: Observations of F-layer electron density profiles modulated by planetary wave type oscillations in the equatorial ionospheric anomaly region, J. Geophys. Res., 110, A12302, https://doi.org/10.1029/2005JA011115, 2005.
Fagundes, P. R., Abalde, J. R., Bittencourt, J. A., Sahai, Y., Francisco, R. G., Pillat, V. G., and Lima, W. L. C.: F layer postsunset height rise due to electric field prereversal enhancement: 2 . Traveling planetary wave ionospheric disturbances and their role on the generation of equatorial spread F, J. Geophys. Res., 114, A12322, https://doi.org/10.1029/2009JA014482, 2009.

Fejer, B. G., Scherliess, L., and de Paula, E. R.: Effects of the vertical plasma drift velocity on the generation and evolution of equatorial spread F, J. Geophys. Res., 104, 19854-19869, 1999.

Forbes, J. M.: Planetary waves in the thermosphere-ionosphere system, J. Geomagn. Geoelectr., 48, 91-98, 1996.

Forbes, J. M.: Wave coupling between the lower and upper atmosphere: case study of an ultra-fast Kelvin wave, J. Atmos. Sol.Terr. Phy., 62, 1603-1621, 2000.

Grinsted, A., Moore, J. C., and Jevrejeva, S.: Application of the cross wavelet transform and wavelet coherence to geophysical time series, Nonlin. Processes Geophys., 11, 561-566, https://doi.org/10.5194/npg-11-561-2004, 2004.

Gurubaran, S., Sridharan, S., Ramkumar T. K., and Rajaram, R.: The mesospheric quasi 2-day wave over Tirunelveli, J. Atmos. Sol.-Terr. Phy., 63, 975-985, 2001.

Haldoupis, C., Pancheva, D., and Mitchell, N. J.: A study of tidal and planetary wave periodicities present in midlatitude sporadic E layers, J. Geophys. Res., 109, A02302, https://doi.org/10.1029/2003JA010253, 2004.

Heelis, R. A., Kendall, P. C., Moffet, R. J., Windle, D. W., and Rishbeth, H.: Electrical coupling of the $\mathrm{E}$ and $\mathrm{F}$ regions and its effect on the F region drifts and winds, Planet. Space Sci., 22, 743-756, 1974.

Kovalam, S., Vincent, R. A., Reid, I. M., Tsuda, T., Ohnishi, K., Nuryanto, A., and Wiryosumarto, H.: Longitudinal variations in planetary wave activity in the equatorial mesosphere, Earth Planets Space, 51, 665-674, 1999.

Laštovička, J.: Forcing of the ionosphere by waves from below, J. Atmos. Sol.-Terr. Phy., 68, 3, 479-497, 2006.

Laštovicka, J., Križan, P., Šauli, P., and Novotná, D.: Persistence of the planetary wave type oscillations in $f_{o} \mathrm{~F} 2$ over Europe, Ann. Geophys., 21, 1543-1552, https://doi.org/10.5194/angeo21-1543-2003, 2003.

Lei, J., Thayer, J. P., Forbes, J. M., Sutton, E. K., and Nerem, R. S.: Rotating solar coronal holes and periodic modulation of the upper atmosphere, Geophys. Res. Lett., 35, L10109, https://doi.org/10.1029/2008GL033875, 2008.

Li, G., Ning, B., Liu, L., Ren, Z., Lei, J., and Su, S.-Y.: The correlation of longitudinal/seasonal variations of evening equatorial prereversal drift and of plasma bubbles, Ann. Geophys., 25, 25712578, https://doi.org/10.5194/angeo-25-2571-2007, 2007.

Li, G., Ning, B., Abdu, M. A., Wan, W., and Hu, L.: Precursor signatures and evolution of post-sunset equatorial spreadF observed over Sanya, J. Geophys. Res., 117, A08321, https://doi.org/10.1029/2012JA017820, 2012.

Li, G., Ning, B., Abdu, M. A., Otsuka, Y., Yokoyama, T., Yamamoto, M., and Liu, L.: Longitudinal characteristics of spread F backscatter plumes observed with the EAR and Sanya VHF radar in Southeast Asia, J. Geophys. Res.-Space, 118, 65446557, https://doi.org/10.1002/jgra.50581, 2013.

Li, G., Ning, B., Chu, Y. H., Reid, I. M., Hu, L., Dolman, B. K., Xiong, J., Jiang, G., Yang, G., and Yan, C.: Structural evolution of long-duration meteor trail irregularities 
driven by neutral wind, J. Geophys. Res., 119, 10348-10357, https://doi.org/10.1002/2014JA020116, 2014.

Li, G., Otsuka, Y., Ning, B., Abdu, M. A., Yamamoto, M., Wan, W., Liu, L., and Abadi, P.: Enhanced ionospheric plasma bubble generation in more active ITCZ, Geophys. Res. Lett., 43, 23892395, https://doi.org/10.1002/2016GL068145, 2016.

Lieberman, R. S. and Riggin, D.: High resolution Doppler imager observations of Kelvin waves in the equatorial mesosphere and lower thermosphere, J. Geophys. Res., 102, 26117-26130, 1997.

Lima, L. M., Batista, P. P., Takahashi, H., and Clemesha, B. R.: Quasi-two-day wave observed by meteor radar at $22.7^{\circ} \mathrm{S}$, J. Atmos. Sol.-Terr. Phy., 66, 529-537, 2004.

Lima, L. M., Medeiros, A. F., De Buriti, R. A., Batista, P. P., Clemesha, B. R., and Takahashi, H.: Mesospheric 2-day waves observed simultaneously in the equatorial and low latitude regions of Brazil, Revista Brasileira de Geofísica, 25, 43-48, 2007.

Lima, L. M., de Oliveira, A. E., Medeiros, A. F., Buriti, R. A., Batista, P. P., Clemesha, B. R., and Takahashi, H.: 3-4 day Kelvin waves observed in the MLT region at $7.4^{\circ} \mathrm{S}$, Brazil, Geofis. Int., 47, 153-160, 2008.

Liu, G., Immel, T. J., England, S. L., Frey, H. U., Mende, S. B., and Kuma, K. K.: Impacts of atmospheric ultrafast Kelvin waves on radio scintillations in the equatorial ionosphere, J. Geophys. Res., 118, 885-891, https://doi.org/10.1002/jgra.50139, 2013.

Lomb, N. R.: Least-squares frequency analysis of unequally spaced data, Astrophys. Space Sci., 39, 447-462, 1976.

Onohara, A. N., Batista, I. S., and Takahashi, H.: The ultra-fast Kelvin waves in the equatorial ionosphere: observations and modeling, Ann. Geophys., 31, 209-215, https://doi.org/10.5194/angeo-31-209-2013, 2013.

Pancheva, D.: Evidence for nonlinear coupling of planetary waves and tides in the lower thermosphere over Bulgaria, J. Atmos. Sol.-Terr. Phy., 62, 115-132, 2000.

Pancheva, D., Mitchell, N., Clark, R. R., Drobjeva, J., and Lastovicka, J.: Variability in the maximum height of the ionospheric F2-layer over Millstone Hill (September 1998-March 2000); influence from below and above, Ann. Geophys., 20, 1807-1819, https://doi.org/10.5194/angeo-20-1807-2002, 2002a.

Pancheva, D., Merzlyakov, E., Mitchell, N. J., Portnyagin, Yu., Manson, A. H., Jacobi, Ch., Meek, C. E., Luo, Y., Clark, R. R., Hocking, W. K., MacDougall, J., Muller, H. G., Kürschner, D., Jones, G. O. L., Vincent, R. A., Reid, I. M., Singer, W., Igarashi, K., Fraser, G. I., Fahrutdinova, A. N., Stepanov, A. M., Poole, L. M. G., Malinga, S. B., Kashcheyev, B. L., and Oleynikov, A. N.: Global-scale tidal variability during the PSMOS campaign of June-August 1999: interaction with planetary waves, J. Atmos. Sol.-Terr. Phy., 64, 1865-1896, 2002b.

Pancheva, D., Haldoupis, C., Meek, C. E., Manson, A. H., and Mitchell, N. J.: Evidence of a role for modulated atmospheric tides in the dependence of sporadic E layers on planetary waves, J. Geophys. Res., 108, 1176, https://doi.org/10.1029/2002JA009788, 2003.

Pancheva, D., Mitchell, N. J., and Younger, P. T.: Meteor radar observations of atmospheric waves in the equatorial mesosphere/lower thermosphere over Ascension Island, Ann. Geophys., 22, 387-404, https://doi.org/10.5194/angeo-22-387-2004, 2004.

Pancheva, D., Mukhtarov, P., Andonov, B., Mitchell, N. J., and Forbes, J. M.: Planetary waves observed by TIMED/SABER in coupling the stratosphere-mesospherelower thermosphere during the winter of 2003/2004: part 1-comparison with the UKMO temperature results, J. Atmos. Sol.-Terr. Phy., 71, 61-74, 2009.

Pancheva, D., Mukhtarov, P., Andonov, B., and Forbes, J. M.: Global distribution and climatological features of the 5-6day planetary waves seen in the SABER/TIMED temperatures (2002-2007), J. Atmos. Sol.-Terr. Phy., 72, 26-37, 2010.

Polekh, N. M., Vergasova, G. V. E., Kazimirovsky, S., Perevalova, N. P., Kurkin, V. I., and Chernigovskaya, M. A.: The PlanetaryWave Activity in Temperatures of the Stratosphere, Mesosphere and in Critical Frequencies of Ionospheric F2 Layer, Int. J. Geophys., 2011, 341935, https://doi.org/10.1155/2011/341935, 2011.

Reinisch, B. W., Abdu, M., Batista, I., Sales, G. S., Khmyrov, G., Bullett, T. A., Chau, J., and Rios, V.: Multistation digisonde observations of equatorial spread F in South America, Ann. Geophys., 22, 3145-3153, https://doi.org/10.5194/angeo-22-31452004, 2004.

Riggin, D., Fritts, D. C., Tsuda, T., Nakamura, T., and Vincent, R. A.: Radar observations of a 3-day Kelvin wave in the equatorial mesosphere, J. Geophys. Res., 102, 26141-26157, 1997.

Rishbeth, H.: Polarization fields produced by winds in the equatorial F region, Planet. Space Sci., 19, 357-369, 1971.

Salby, M. L., Hartmann, D. L., Bailey, P. L., and Gille, J. C.: Evidence for equatorial Kelvin modes in Nimbus-7 LIMS, J. Atmos. Sci., 41, 220-235, 1984.

Scali, J. L., Reinisch, B. W., Heinselman, C. J., and Bullett, T.: Coordinated Digisonde and incoherent scatter radar $\mathrm{F}$ region drift measurements at Sondre Stromfjord, Radio Sci., 30, 1481-1498, https://doi.org/10.1029/95RS01730, 1995.

Scargle, J. D.: Studies in astronomical time series analysis. II. Statistical aspects of spectral analysis of unevenly spaced data, Astrophys. J., 263, 835-853, 1982.

Sridharan, S., Gurubaran, S., and Rajaram, R.: Radar observations of the 3.5-day ultra-fast Kelvin wave in the low-latitude mesosphere region, J. Atmos. Sol.-Terr. Phy., 64, 1241-1250, 2002.

Takahashi, H., Buriti, R. A., Gobbi, D., and Batista, P. P.: Equatorial planetary wave signatures observed in mesospheric airglow emissions, J. Atmos. Sol.-Terr. Phy., 64, 1263-1272, 2002.

Takahashi, H., Lima, L. M., Wrasse, C. M., Abdu, M. A., Batista, I. S., Gobbi, D., Buriti, R. A., and Batista, P. P.: Evidence on 2-4 day oscillations of the equatorial ionosphere $h^{\prime} \mathrm{F}$ and mesospheric airglow emission, Geophys. Res. Lett., 32, L12102, https://doi.org/10.1029/2004GL022318, 2005.

Takahashi, H., Wrasse, C. M., Pancheva, D., Abdu, M. A., Batista, I. S., Lima, L. M., Batista, P. P., Clemesha, B. R., and Shiokawa, K.: Signatures of 3-6 day planetary waves in the equatorial mesosphere and ionosphere, Ann. Geophys., 24, 3343-3350, https://doi.org/10.5194/angeo-24-3343-2006, 2006.

Takahashi, H., Wrasse, C. M., Fechine, J., Pancheva, D., Abdu, M. A., Batista, I. S., Lima, L. M., Batista, P. P., Clemesha, B. R., Schuch, N. J., Shiokawa, K., Gobbi, D., Mlynczak, M. G., and Russell, J. M.: Signatures of ultra fast Kelvin waves in the equatorial middle atmosphere and ionosphere, Geophys. Res. Lett. 34, L11108, https://doi.org/10.1029/2007GL029612, 2007.

Takahashi, H., Abdu, M. A., Wrasse, C. M., Fechine, J., Batista, I. S., Pancheva, D., Lima, L. M., Batista, P. P., Clemesha, B. R., Shiokawa, K., Gobbi, D., Mlynczak, M. G., and Russel, J. M.: Possible influence of ultra-fast Kelvin wave on the equatorial 
ionosphere evening uplifting, Earth Planets Space, 61, 455-462, 2009.

Torrence, C. and Compo, G.: A practical guide to wavelet analysis, B. Am. Meterol. Soc., 79, 61-78, 1998.

Tsunoda, R. T.: Seeding of equatorial plasma bubbles with electric fields from and Es-layer instability, J. Geophys. Res., 112, A06304, https://doi.org/10.1029/2006JA012103, 2007.

Vincent, R. A.: Long-period motions in the equatorial mesosphere, J. Atmos. Terr. Phys., 55, 1067-1080, 1993.

Vincent, R. A. and Lesicar, D.: Dynamics of the equatorial mesosphere: first results with a new generation partial reflection radar, Geophys. Res. Lett., 18, 825-828, 1991.

Xu, J., Smith, A. K., Jiang, G., Yuan, W., and Gao, H.: Features of the seasonal variation of the semidiurnal, terdiurnal and 6-h components of ozone heating evaluated from Aura/MLS observations, Ann. Geophys., 30, 259-281, https://doi.org/10.5194/angeo-30-259-2012, 2012.
Xu, J., Smith, A. K., Liu, M., Liu, X., Gao, H., Jiang, G., and Yuan, W.: Evidence for non-migrating tides produced by the interaction between tides and stationary planetary waves in the stratosphere and lower mesosphere, J. Geophys. Res.-Atmos., 119, 471-489, https://doi.org/10.1002/2013JD020150, 2014.

Younger, P. T. and Mitchell, N. J.: Waves with period near 3 days in the equatorial mesosphere and lower thermosphere over Ascension Island, J. Atmos. Sol.-Terr. Phy., 68, 369-378, 2006.

Zhu, Z., Chen, K., Lan, J., and Sun, F.: F3 Layer Feature under Low and Medium Solar Activity Observed at a Chinese Low Latitude Station Fuke, Adv. Space Res., 52, 383-390, https://doi.org/10.1016/j.asr.2013.03.031, 2013.

Zhu, Z., Lan, J., Luo, W., Sun, F., Chen, K., and Chang, S.: Statistical characteristics of ionogram spread-F and satellite traces over a Chinese low-latitude station Sanya, Adv. Space Res., 56 , 1911-1921, https://doi.org/10.1016/j.asr.2015.03.038, 2015. 